\title{
What's in a name? Lower extremity fracture eponyms (Part 2)
}

\author{
Philip Kin-Wai Wong ${ }^{1}$, Tarek N Hanna ${ }^{2 *}$, Waqas Shuaib ${ }^{3}$, Stephen M Sanders ${ }^{4}$ and Faisal Khosa ${ }^{2}$
}

\begin{abstract}
Eponymous extremity fractures are commonly encountered in the emergency setting. Correct eponym usage allows rapid, succinct communication of complex injuries. We review both common and less frequently encountered extremity fracture eponyms, focusing on imaging features to identify and differentiate these injuries. We focus on plain radiographic findings, with supporting computed tomography (CT) images. For each injury, important radiologic descriptors are discussed which may need to be communicated to clinicians. Aspects of management and follow-up imaging recommendations are included. This is a two-part review: Part 1 focuses on fracture eponyms of the upper extremity, while Part 2 encompasses fracture eponyms of the lower extremity.
\end{abstract}

Keywords: Eponyms; Fractures; Lower extremities; Imaging

\section{Introduction}

Eponyms are embedded throughout medicine; they can be found in medical literature, textbooks, and even mass media. Their use allows physicians to quickly provide a concise description of a complex injury pattern. Eponymous extremity fractures are commonly encountered in the emergency setting and are frequently used in interactions amongst radiologists, emergency clinicians, and orthopedists. Unfortunately, the imprecise use of eponyms can result in confusion and miscommunication [1]. In this two-part series, our goal is to provide emergency providers with consistent, accurate definitions and depictions of commonly and less frequently encountered extremity fracture eponyms, keying in on important imaging features that differentiate these fractures. We illustrate fundamental descriptors of each injury that a clinician should expect in a radiology report. We also briefly review the mechanism of each injury, associated complications, any follow-up imaging needed, and treatment.

\footnotetext{
* Correspondence: tarek.hanna@emory.edu

${ }^{2}$ Division of Emergency Radiology, Department of Radiology and Imaging

Sciences, Emory University Hospital Midtown, 550 Peachtree Street NE,

Atlanta, GA 30308, USA

Full list of author information is available at the end of the article
}

\section{Review: Lower extremity fracture eponyms Pipkin fracture}

Femoral head fractures are relatively uncommon and are typically associated with hip dislocations after severe high-impact trauma such as a motor vehicle collision. Femoral head fractures are commonly grouped into the Pipkin classification (see Table 1) after the work of the orthopedic surgeon Garrett Pipkin in 1957 (Fig. 1) [2]. Hip fracture-dislocations are clinical emergencies requiring immediate reduction to prevent osteonecrosis. Anterior-posterior (AP) and lateral radiographs will show posterior dislocation of the femoral head, which appears smaller than the contralateral normal side. If there is suspicion for an acetabular fracture, then Judet oblique views should be obtained. Associated fractures should be identified, with particular attention to the femoral neck [3, 4]. CT of the pelvis should be obtained after closed reduction or prior to open reduction of an irreducible injury in order to better characterize the pattern, degree of comminution, presence of loose bodies, and the congruity of the hip joint [5]. Emergent open reduction is indicated when there is nonanatomic reduction of the femoral head, hip joint instability, or the presence of intraarticular fragments, which prevent joint congruity [3, 4, 6, 7].

\section{实}

(c) 2015 Wong et al. This is an Open Access article distributed under the terms of the Creative Commons Attribution License (http://creativecommons.org/licenses/by/4.0), which permits unrestricted use, distribution, and reproduction in any medium, provided the original work is properly credited. 
Table 1 Pipkin classification

\begin{tabular}{ll}
\hline Type I & Inferior to the fovea capitis femoris \\
Type II & Superior to the fovea capitis femoris \\
Type III & Type I or type II with associated femoral neck fracture \\
Type IV & Type I or type II with associated acetabular rim fracture \\
\hline
\end{tabular}

\section{Segond fracture}

First described by the French surgeon Paul Segond in 1879, the Segond fracture may be the best known avulsion fracture of the lower extremity [8]. This eponym refers to a small, vertical avulsion of the proximal lateral tibia just inferior to the tibial plateau Fig. 2. The Segond fracture results from varus stress on an internally rotated knee [9]. AP radiographs are sufficient for diagnosis. The fracture fragment is usually crescentic with approximately $3 \mathrm{~mm}$ displacement from the tibial metaphysis [10]. It is important to distinguish the irregular tibial donor site so as to not confuse the Segond fracture with an avulsion fracture of the Gerdy tubercle, which is more anterior and distal and can be distinguished on the lateral radiograph. Although a subtle finding, the Segond fracture is of considerable clinical significance in its extremely high association with tears of the anterior cruciate ligament (ACL) (75-100\% of cases), meniscal tears (66\%), as well as avulsion of the fibular attachment of the long head of the biceps and fibular collateral ligament [11, 12]. Segond fractures should prompt non-emergent $\mathrm{MR}$ imaging of the knee [8, 9, 13]. There is more recent recognition of a "reverse Segond fracture," consisting of a mirror-image crescentic fracture of the medial tibial plateau. This entity has a

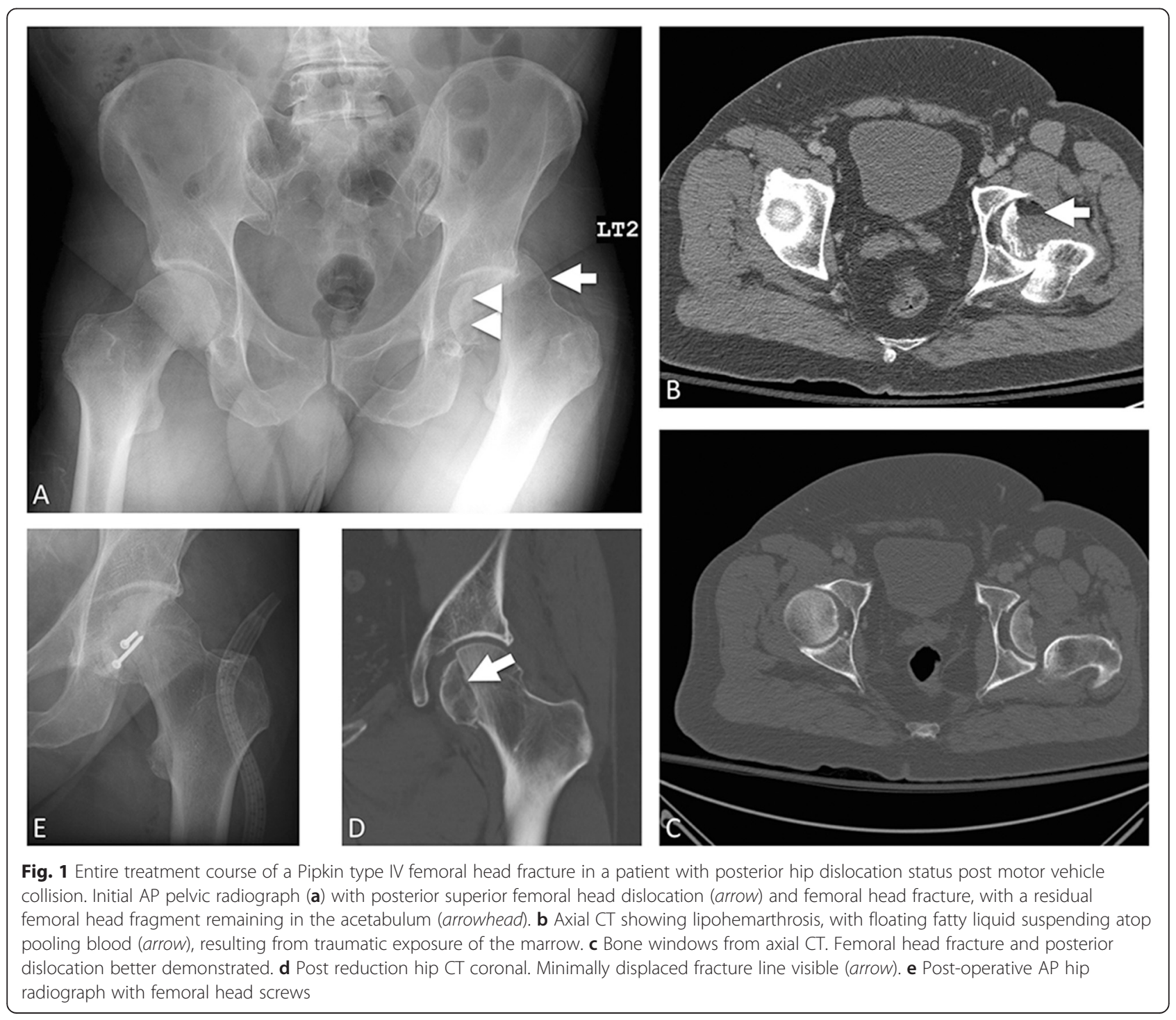



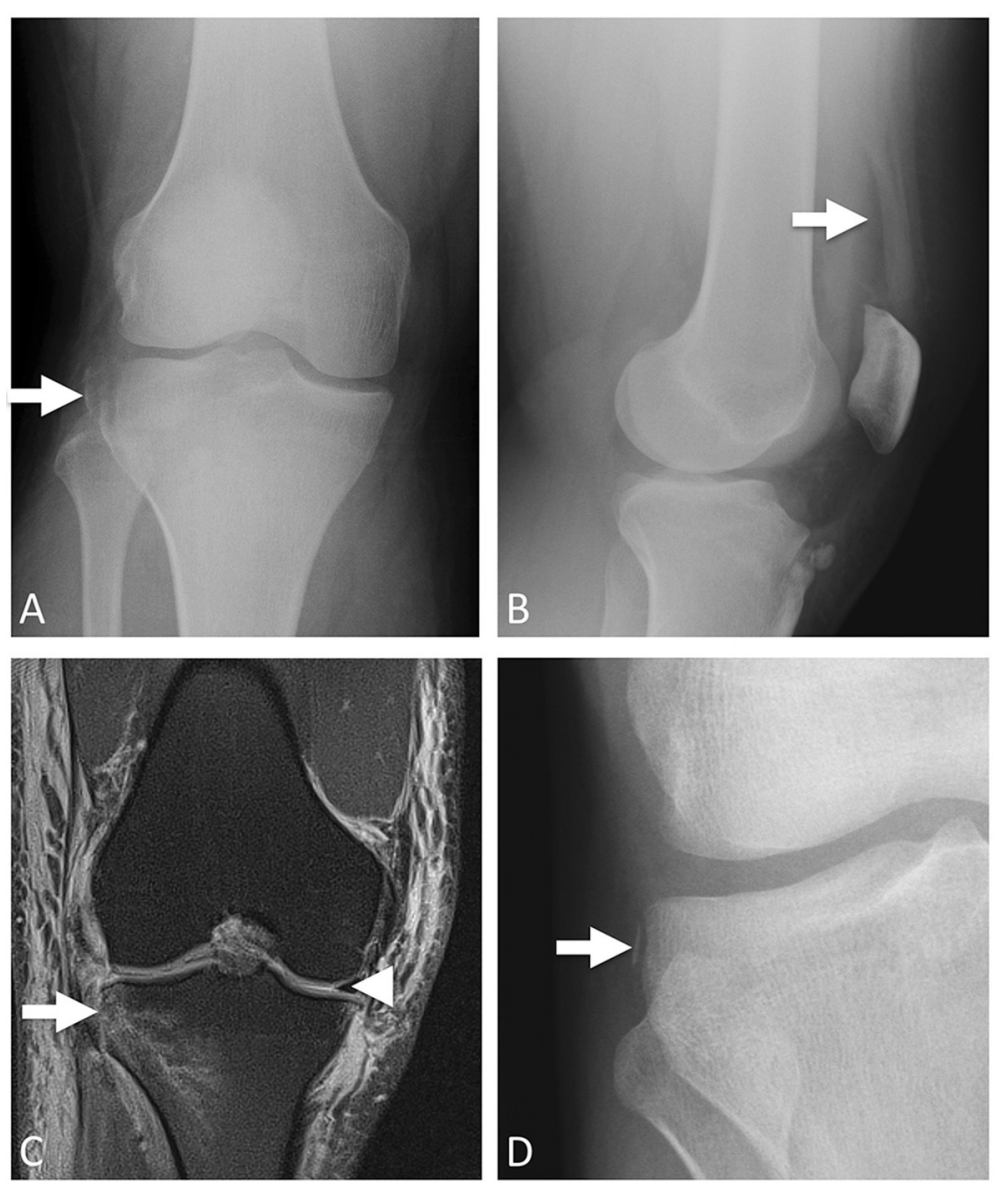

Fig. 2 Segond fracture. a AP knee radiograph with large Segond fracture (arrow). b Lateral knee radiograph in the same patient shows a lipohemarthrosis, which confirms fracture-induced exposure of the fatty marrow cavity to the articular space. c Coronal proton density (PD) fat saturated images showing the Segond fracture (arrow). The bright signal in this image is all edema, since the fat signal is suppressed. The patient had an ACL tear (not shown). Note the presence of the medial meniscus (arrowhead) and the absence of the lateral meniscus on the same image, confirming a complete lateral meniscus tear with displacement. $\mathbf{d}$ Another patient AP knee radiograph. Thin, small Segond fracture (arrow). This patient did have an ACL tear; this shows how subtle these fractures can be but still be associated with substantial injury

weaker association with posterior cruciate ligament (PCL) injury and medial meniscus tears and should also prompt non-emergent MR imaging [14]. Treatment involves repair of the associated ligamentous or meniscal tears.

\section{Maisonneuve fracture}

The Maisonneuve fracture, named after the French surgeon Jacque Gilles Maisonneuve, is a spiral fracture of the proximal third of the fibula with associated disruption of the distal tibiofibular syndesmosis Fig. 3 [15]. The fracture results from an injury cascade involving the ankle, where external rotation is applied to a pronated or supinated foot [16]. Rupture of the stabilizing ligaments of the distal tibiofibular syndesmosis will result in widening of the ankle mortise on radiographs. Additional findings such as avulsion fracture of the medial or posterior malleoli, or tear of the deltoid ligaments may also be present $[17,18]$. A Maisonneuve fracture implies an unstable ankle, despite normal position of the talus and ankle mortise. It is important to remember that non-weight-bearing views, the ones most often ordered in the emergency department, may not demonstrate widening of the ankle mortise. Maisonneuve fractures may be missed as patient and physicians focus attention on the ankle as the major site of complaint and patients may not complain of pain upon palpation of the proximal fibula [16]. Maisonneuve fractures should be suspected whenever there is lateral talar displacement or tibiofibular widening without distal fibular fracture [19]. In these cases, stress radiographs and full-length tibiofibular radiographs should 

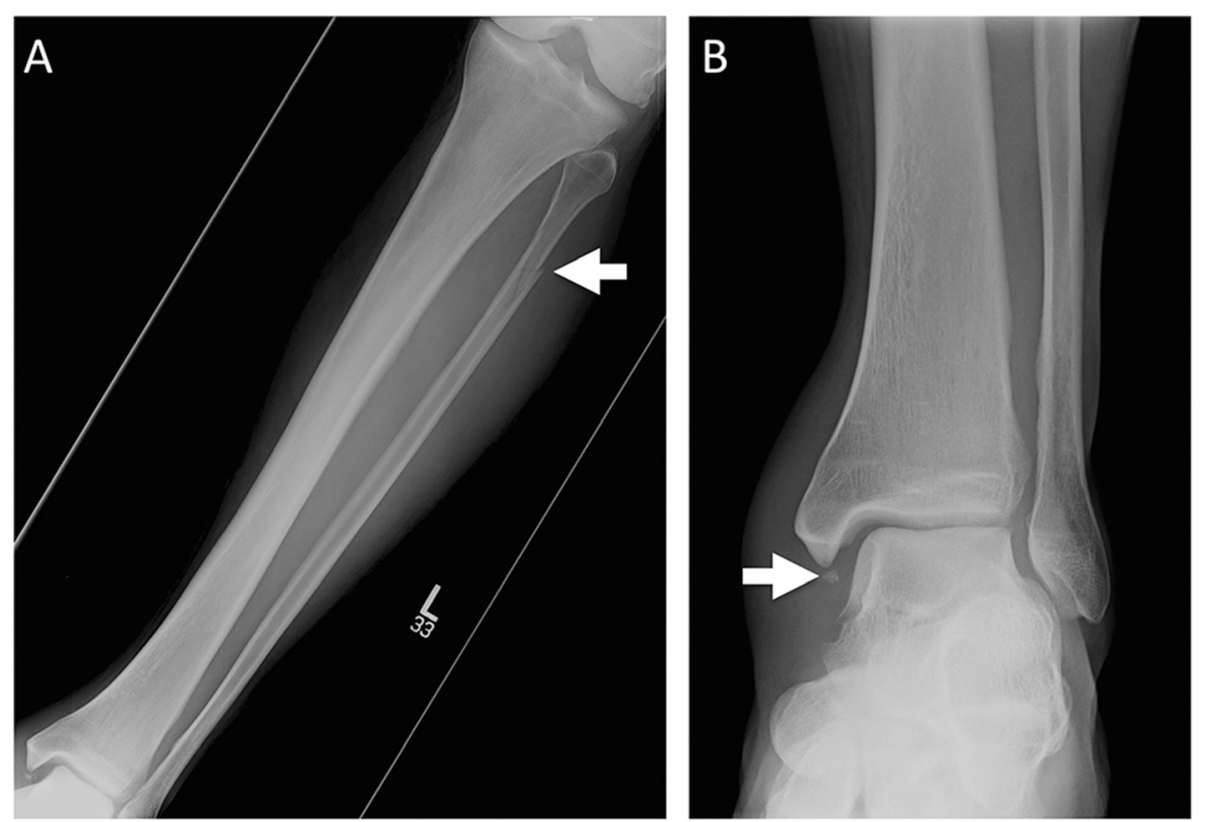

Fig. 3 Maisonneuve fracture. a AP tibula/fibula radiograph with minimally displaced fracture of the proximal fibular shaft (arrow). b AP ankle radiograph in the same patient. Soft tissue swelling overlying the lateral malleolus, with avulsion fracture of the inferior aspect of the medial malleolus (arrow). This patient had confirmed disruption of the syndesmosis, with subsequent syndesmotic fixation

be obtained [20]. The goal of treatment is to maintain a normal ankle mortise, which usually requires open reduction due to the frequency of ankle instability [17].

\section{Gosselin fracture}

The French surgeon Leon Athanese Gosselin first described the Gosselin fracture [15] as a V-shaped fracture

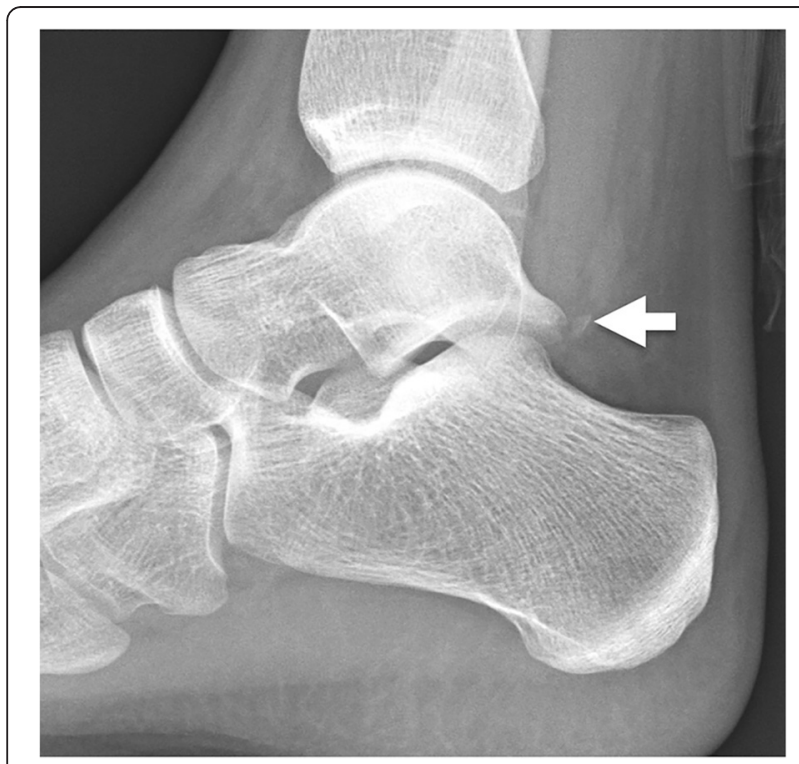

Fig. 4 Shepherds fracture. Fracture of the lateral tubercle of the posterior process of the talus (arrow) of the distal tibia with extension into the tibial plafond, dividing it into anterior and posterior segments [15]. Distal tibia fractures that involve the articular surface or tibial plafond are also known under the umbrella term "Pilon fractures." Pilon fractures are quite complex with many variations, usually as a result of axial loading of the weight-bearing surface of the tibia. The degree of comminution, soft tissue swelling, and articular incongruity dictate surgical management which is initially external fixation followed by delayed definitive fixation if the soft tissue swelling is severe [21].

\section{Pott fracture}

The Pott fracture has inappropriately evolved into a term to describe a bimalleolar fracture. Percival Pott originally described it in 1768 as a fracture of the distal fibula, 2-3 in. proximal to the ankle joint, with an associated tear of the deltoid ligaments and lateral displacement of the talus [22-24]. This type of injury results from a direct force resulting in eversion at the ankle [25]. Due to the often incorrect usage of this eponym and the development of newer more detailed ankle fracture classification systems, we suggest this eponym not be used in clinical practice.

\section{Shepherd fracture}

The Shepherd fracture is named after the Canadian surgeon Francis Shepherd and refers to a fracture of the lateral tubercle of the posterior process of the talus Fig. 4 


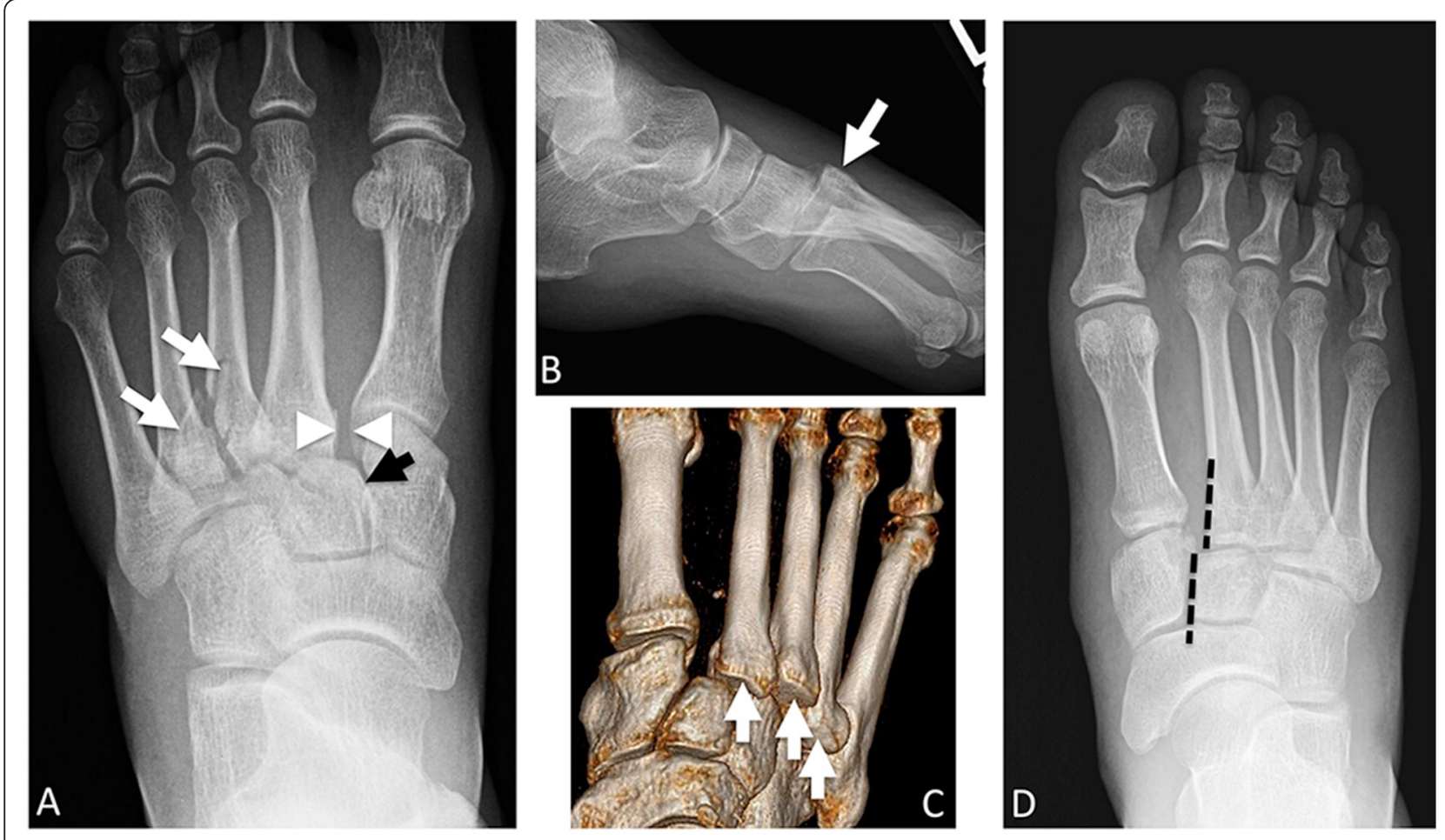

Fig. 5 Lisfranc fracture-dislocation. a AP view of the foot with widening of the space between the first and second metatarsal bases (arrowheads). Misalignment of the second metatarsal base from the middle cuneiform (medial margin of middle cuneiform demarcated with black arrow). Fractures of the bases of the third and fourth metacarpals (white arrows). b Lateral view in the same patient shows dorsal displacement of the second to fourth metatarsal bases (arrow). c Volume rendered CT reformat in a different patient with dislocation of the second, third, and fourth metatarsal bases. $\mathbf{d}$ Different patient. Additional Lisfranc fracture dislocation. Here, the misalignment of the second metatarsal base from the middle cuneiform is shown with dashed lines - these should be in the same line. Again, there is widening of the first and second metatarsal base interspace
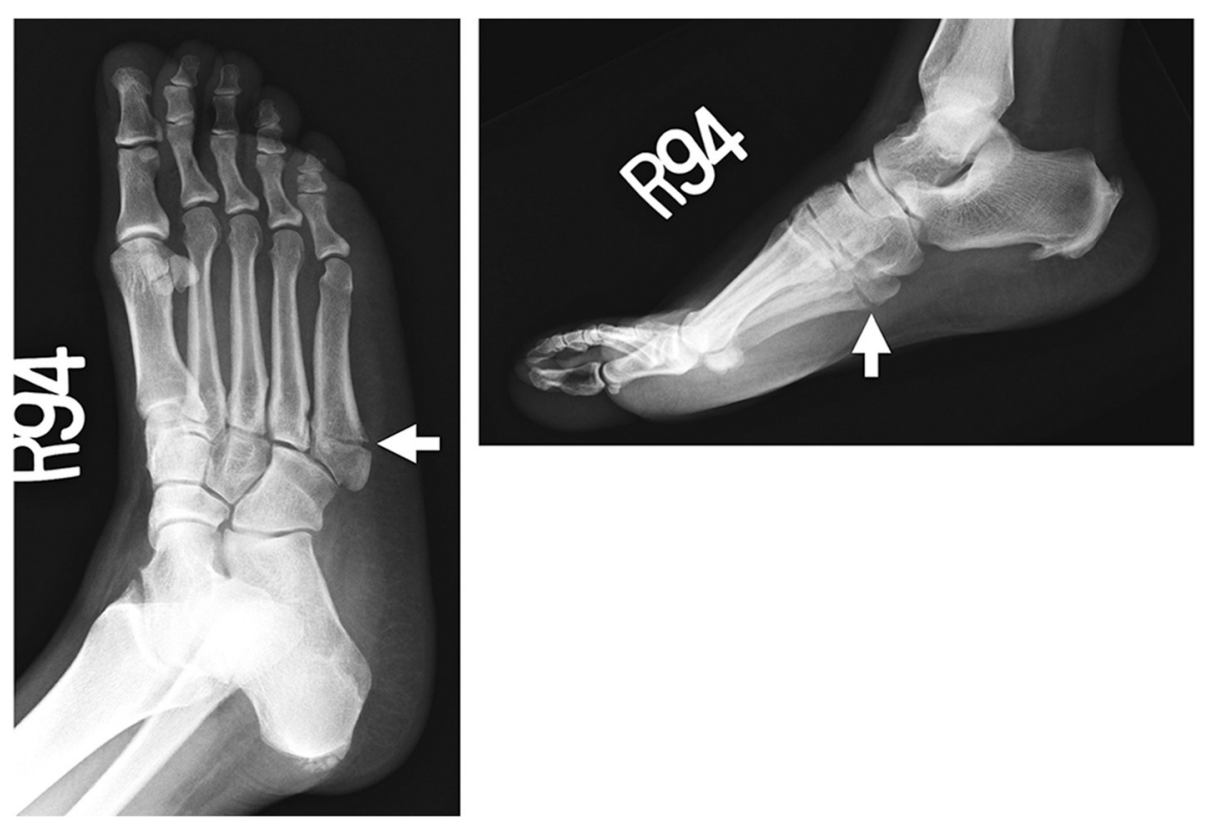

Fig. 6 Jones fracture. Transverse fracture $2 \mathrm{~cm}$ from the base of the fifth metatarsal 
[26], typically resulting from ankle inversion, forced plantar flexion, or direct compression injury in which the posterior talofibular ligament avulses the tubercle [27]. This fracture is best seen on lateral radiographs [28], although the sensitivity of radiographs in recognizing talar fractures is only $78 \%$ [29]. Furthermore, in the setting of trauma, talar and other associated fractures may not be completely identified on plain radiographs; thus, CT should be considered for complete evaluation [29-31]. Of note, Shepherd's fracture may be mistaken for an os trigonum, an accessory bone from a secondary ossification center posterior to the lateral tubercle, which is a normal finding $[27,28,32]$. Typically, an os trigonum is rounded or oval with smooth corticated edges as opposed to a sharply marginated non-corticated irregular fracture. In equivocal cases, CT, MR, or even a technetium bone scan of the ankle may be helpful [32]. Complications of talar fractures include chronic pain, arthrosis, and rarely avascular necrosis [27]. Treatment of the Shepherd fracture is typically immobilization, although depending on symptoms, delayed excision of the fragments may be necessary [33].

\section{Tillaux fracture}

The Tillaux fracture was described by Sir Astley Cooper in 1822 and further characterized by Paul Tillaux in cadaveric studies in 1845. The Tillaux fracture is an avulsion fracture of the anterolateral tubercle of the distal tibia caused by a pull of the anteroinferior tibiofibular ligament during external rotation [34]. This typically occurs in adolescent patients, as the ligament is usually stronger than the anterolateral epiphysis, which at this time of development, is open and susceptible to injury [35]. The Tillaux fracture is a Salter Harris type III injury and is often apparent on AP, lateral, and mortise conventional radiographic views. CT has been found to have better sensitivity in diagnosing Tillaux fractures as well as detecting fracture displacement greater than $2 \mathrm{~mm}$, which is the indication for open reduction [36-39]. Growth arrest, degenerative arthritis, and ankle instability are feared complications $[35,36,40]$.

\section{Lisfranc fracture}

The Lisfranc joint is the tarsometatarsal joint complex which joins the forefoot and midfoot and is named after Jacque Lisfranc de Saint-Martin, a famous French surgeon who performed forefoot disarticulations at this joint [41]. The articulation consists of nine osseous structures: five metatarsals (M1-M5), three cuneiforms (C1-C3), and the cuboid, with further stabilization from a complex arrangement of ligaments. Lisfranc injuries can be subdivided into Lisfranc fracture-displacements due to high-impact injuries versus Lisfranc midfoot sprains due to low-impact injuries. Radiography is the initial imaging study of choice [41]. These fractures may be subtle. A small chip fracture at the M1-M2 interspace, known as the "fleck sign," may be the only indicator of Lisfranc injury [41-43]. The gap between $\mathrm{C} 1$ and M2 should be less than $2 \mathrm{~mm}[44,45]$. Malalignment or C1-M2 widening suggests Lisfranc injury Fig. 5. Lateral views can show step-offs at the tarsometatarsal joint [46]. Equivocal cases should be further evaluated with weight-bearing or stress radiographs searching for diastasis and step-offs on stress views, that were not seen on resting views $[41,42,46]$. In cases involving a serious mechanism, CT may be beneficial to diagnose or further characterize Lisfranc injuries. MR imaging is recommended in lowgrade midfoot sprains due to its superior sensitivity in the detection of ligamentous injuries. Occasionally, when radiography, CT, or MRI are equivocal, bone scintigraphy may show increased radiotracer uptake, suggestive of Lisfranc injuries [41]. Delayed diagnosis may lead to poor outcomes

Table $\mathbf{2}$ Lower extremity fracture eponyms

\begin{tabular}{|c|c|}
\hline Lower extremity fracture eponyms & Fracture pattern \\
\hline$\overline{\text { Pipkin }}$ & Femoral head fracture typically associated with hip dislocation. See Table 1 for types. \\
\hline Segond & $\begin{array}{l}\text { Small avulsion fracture of the proximal lateral tibia just inferior to the tibial plateau. High association } \\
\text { with ligamentous injury. }\end{array}$ \\
\hline Maisonneuve & $\begin{array}{l}\text { Spiral fracture of the proximal third of the fibula with associated disruption of the distal } \\
\text { tibiofibular syndesmosis }\end{array}$ \\
\hline Gosselin & V-shaped intra-articular fracture of the distal tibia \\
\hline Pott & Fracture of the distal fibula, 2-3 in. proximal to the ankle joint. \\
\hline Shepherd & Fracture of the lateral tubercle of the posterior talar process \\
\hline Tillaux & Avulsion fracture of the anterolateral tubercle of the distal tibia \\
\hline Lisfranc & Fracture-dislocation of the tarsometatarsal joints \\
\hline Chopart & Fracture-dislocation of the midtarsal joint spaces \\
\hline Jones & Transverse fracture involving the fifth metatarsal proximal shaft \\
\hline
\end{tabular}


such as arch deformity, chronic pain, or osteoarthritis. For mild Lisfranc injuries with less than $2 \mathrm{~mm}$ of diastasis between the first and second metatarsals, nonoperative treatment with immobilization can be pursued. Otherwise, instability or frank dislocation should be treated surgically with either closed reduction under fluoroscopy and fixation with percutaneous screws or open reduction and internal fixation $[41,45]$.

\section{Chopart fracture-dislocation}

The Chopart joint, also known as the midtarsal or transverse tarsal joint, consists of the calcaneocuboid and talonavicular joints, which join the midfoot and hindfoot. This space was described by the French surgeon Francois Chopart as another potential area for disarticulation [47]. In significant high-energy trauma, these joints may be displaced [48], with associated navicular, cuboid, calcaneal, or talar fractures. This constellation is known as the Chopart fracture-dislocation. Displacement may be in any direction according to the direction of the force $[48,49]$. Due to the low sensitivity of radiography in the detection of midfoot fractures, evaluation with $\mathrm{CT}$ is recommended, as untreated midfoot fractures often have poor outcomes such as chronic pain, arthritis, and decreased functional ability [50]. Urgent reduction is necessary for treatment of Chopart fracture-dislocations, with subsequent open reduction if anatomical alignment cannot be maintained [50-52].

\section{Jones fracture}

Sir Robert Jones first described his own fracture of the fifth metatarsal, which occurred while dancing, as a transverse fracture at the proximal three-fourth segment of the shaft distal to the styloid Fig. 6 [53, 54]. The Jones fracture should be differentiated from the "Dancer's fracture," (or pseudo-Jones fracture), which is an avulsion fracture of the fifth metatarsal base, proximal to the more diaphyseal Jones fracture $[13,55]$. The term Jones fracture was later defined as a transverse fracture at the metaphyseal/diaphyseal junction without distal extension beyond the fourth to fifth intermetatarsal articulation [56, 57]. Three views of the foot-AP, lateral, and oblique radiographs-are sufficient for diagnosis of a Jones fracture. Jones fractures take longer to heal than do avulsion fractures and have high rates of nonunion, delayed union, or refracture due to the watershed blood supply [53, 57]. Jones fractures can be treated with non-weight-bearing leg casting versus operative treatment with intramedullary screw fixation.

\section{Conclusions}

Fracture eponyms are frequently used in everyday practice by radiologists, emergency clinicians, and orthopedists. Accurate knowledge of eponymous fractures can facilitate patient care by helping radiologists and emergency clinicians efficiently convey a great deal of information in an extremely concise manner. This concludes our two-part review of eponymous fractures of the extremities. For a brief summary of the reviewed lower extremity fracture eponyms, please see Table 2.

\section{Abbreviations}

ACL: Anterior cruciate ligament; AP: Anterior-posterior; C1: Medial cuneiform C2: Middle cuneiform; C3: Lateral cuneiform; CT: Ctomography; M1-M5: First through fifth metatarsals; MRI: Magnetic resonance imaging; PCL: Posterior cruciate ligament.

\section{Competing interests}

The authors declare that they have no competing interests. There was no commercial funding for this study. The authors have full control over all the data. The study will not be published elsewhere in any language without the consent of the copyright owners.

\section{Authors' contributions}

PW contributed in the review of the literature and helped draft the manuscript. $\mathrm{TH}$ conceived of the review and participated in its design and coordination, helped draft the manuscript, and compiled the relevant images. WS participated in the design and coordination and helped draft the manuscript. SS helped draft the manuscript. FK conceived of the review and helped draft the manuscript. All authors read and approved the final manuscript.

\section{Authors' information}

Faisal Khosa is the American Roentgen Ray Society scholar (2013-2015).

\section{Author details}

${ }^{1}$ Department of Radiology and Imaging Sciences, Emory University School of Medicine, 1364 Clifton Road, Atlanta, GA 30322, USA. ²Division of Emergency Radiology, Department of Radiology and Imaging Sciences, Emory University Hospital Midtown, 550 Peachtree Street NE, Atlanta, GA 30308, USA.

${ }^{3}$ Department of Radiology and Imaging Sciences, Emory University Hospital Midtown, 550 Peachtree Street NE, Atlanta, GA 30308, USA. ${ }^{4}$ Department of Emergency Medicine, Emory University Hospital, 531 Asbury Circle, Annex Building, Suite N340, Atlanta, GA 30322, USA.

Received: 11 May 2015 Accepted: 16 July 2015

Published online: 25 July 2015

\section{References}

1. Woywodt A, Matteson E. Should eponyms be abandoned? Yes. BMJ. 2007;335(7617):424

2. Pipkin G. Treatment of grade IV fracture-dislocation of the hip. J Bone Joint Surg Am. 1957;39-a(5):1027-42. passim.

3. Droll KP, Broekhuyse H, O'Brien P. Fracture of the femoral head. J Am Acad Orthop Surg. 2007;15(12):716-27.

4. Ross JR, Gardner MJ. Femoral head fractures. Curr Rev Musculoskelet Med. 2012;5(3):199-205.

5. Moed BR, Maxey JW. Evaluation of fractures of the femoral head using the CT-directed pelvic oblique radiograph. Clin Orthop Relat Res. 1993:296:161-7.

6. Lin D, Lian K, Chen Z, et al. Emergent surgical reduction and fixation for Pipkin type I femoral fractures. Orthopedics. 2013;36(6):778-82.

7. Yu JS. Hip and femur trauma. Semin Musculoskelet Radiol. 2000;4(2):205-20.

8. Gottsegen CJ, Eyer BA, White EA, Learch TJ, Forrester D. Avulsion fractures of the knee: imaging findings and clinical significance. Radiographics. 2008;28(6):1755-70.

9. Venkatasamy A, Ehlinger M, Bierry G. Acute traumatic knee radiographs: beware of lesions of little expression but of great significance. Diagn Interv Imaging. 2014;95(6):551-60.

10. Capps GW, Hayes CW. Easily missed injuries around the knee. Radiographics. 1994;14(6):1191-210

11. Goldman AB, Pavlov $H$, Rubenstein D. The Segond fracture of the proximal tibia: a small avulsion that reflects major ligamentous damage. AJR Am J Roentgenol. 1988;151(6):1163-7.

12. Weber WN, Neumann CH, Barakos JA, et al. Lateral tibial rim (Segond) fractures: MR imaging characteristics. Radiology. 1991;180(3):731-4. 
13. Stevens MA, El-Khoury GY, Kathol MH, Brandser EA, Chow S. Imaging features of avulsion injuries. Radiographics. 1999;19(3):655-72.

14. Escobedo EM, Mills WJ, Hunter JC. The "reverse Segond" fracture: association with a tear of the posterior cruciate ligament and medial meniscus. AJR Am J Roentgenol. 2002;178(4):979-83.

15. Hunter TB, Peltier LF, Lund PJ. Radiologic history exhibit. Musculoskeletal eponyms: who are those guys? Radiographics. 2000;20(3):819-36.

16. Millen JC, Lindberg D. Maisonneuve fracture. J Emerg Med. 2011:41(1):77-8.

17. Kalyani B, R.C., Giannoudis P. The Maisonneuve injury: a comprehensive review. Orthopedics. 2010. 33(3)190-195

18. Madhusudhan TR, Medapati Dhana SR, Smith IC. Report of the case of a rare pattern of Maisonneuve fracture. J Foot Ankle Surg. 2008;47(2):160-2.

19. Hanson JA, Fotoohi M, Wilson AJ. Maisonneuve fracture of the fibula: implications for imaging ankle injury. AJR Am J Roentgenol. 1999;173(3):702.

20. Taweel NR, Raikin SM, Karanjia HN, Ahmad J. The proximal fibula should be examined in all patients with ankle injury: a case series of missed Maisonneuve fractures. J Emerg Med. 2013;44(2):e251-5.

21. Topliss CJ. Anatomy of Pilon fractures of the distal tibia. J Bone Joint Surg (Br). 2005;87-B(5):692-7.

22. Pott P. Some few general remarks on fractures and dislocations. 1758. Clin Orthop Relat Res. 2007:458:40-1.

23. Somford MP, Wiegerinck Jl, Hoornenborg D, van den Bekerom MP. Ankle fracture eponyms. J Bone Joint Surg Am. 2013:95(24):e198. 1-7.

24. Wilson FC. Fractures of the ankle: pathogenesis and treatment. J South Orthop Assoc. 2000;9(2):105-15.

25. Heath $\mathrm{HH}$, Selby CD. XV. The open method in the treatment of Pott's fracture of the leg. Ann Surg. 1908:47(1):98-107.

26. Shepherd FJ. A hitherto undescribed fracture of the astragalus. J Anat Physiol. 1882;17(Pt 1):79.

27. Summers NJ, Murdoch MM. Fractures of the talus: a comprehensive review. Clin Podiatr Med Surg. 2012:29(2):187-203. vii.

28. Kou JX, Fortin PT. Commonly missed peritalar injuries. J Am Acad Orthop Surg. 2009;17(12):775-86

29. Dale JD, Ha AS, Chew FS. Update on talar fracture patterns: a large level I trauma center study. AJR Am J Roentgenol. 2013;201(5):1087-92.

30. Haddad FS, Bartlett M, Singh D. The sequelae of posterior talar fractures. Injury. 2000;31(2):107-11.

31. Early JS. Talus fracture management. Foot Ankle Clin. 2008;13(4):635-57.

32. Karasick D, Schweitzer ME. The os trigonum syndrome: imaging features. AJR Am J Roentgenol. 1996;166(1):125-9.

33. Bykov Y. Fractures of the talus. Clin Podiatr Med Surg. 2014;31(4):509-21.

34. Protas JM, Kornblatt BA. Fractures of the lateral margin of the distal tibia. The Tillaux fracture. Radiology. 1981;138(1):55-7.

35. Rosenbaum AJ, DiPreta JA, Uhl RL. Review of distal tibial epiphyseal transitional fractures. Orthopedics. 2012;35(12):1046-9.

36. Crawford $\mathrm{AH}$. Triplane and Tillaux fractures: is a $2 \mathrm{~mm}$ residual gap acceptable? J Pediatr Orthop. 2012;32 Suppl 1:S69-73.

37. Haapamaki W, Kiuru MJ, Koskinen SK. Ankle and foot injuries: analysis of MDCT findings. AJR Am J Roentgenol. 2004;183(3):615-22.

38. Horn BD, Crisci K, Krug M, Pizzutillo PD, MacEwen GD. Radiologic evaluation of juvenile Tillaux fractures of the distal tibia. J Pediatr Orthop. 2001:21(2):162-4

39. Kaya A, Altay T, Ozturk H, Karapinar L. Open reduction and internal fixation in displaced juvenile Tillaux fractures. Injury. 2007:38(2):201-5.

40. Duchesneau S, Fallat LM. The Tillaux fracture. J Foot Ankle Surg. 1996:35(2):127-33. discussion 189.

41. Siddiqui NA, Galizia MS, Almusa E, Omar IM. Evaluation of the tarsometatarsal joint using conventional radiography, $\mathrm{CT}$, and MR imaging. Radiographics. 2014;34(2):514-31.

42. Hatem SF. Imaging of Lisfranc injury and midfoot sprain. Radiol Clin North Am. 2008:46(6):1045-60. vi.

43. Myerson MS, Fisher RT, Burgess AR, Kenzora JE. Fracture dislocations of the tarsometatarsal joints: end results correlated with pathology and treatment. Foot Ankle. 1986;6(5):225-42.

44. Foster SC, Foster RR. Lisfranc's tarsometatarsal fracture-dislocation. Radiology. 1976;120(1):79-83.

45. Kalia V, Fishman EK, Carrino JA, Fayad LM. Epidemiology, imaging, and treatment of Lisfranc fracture-dislocations revisited. Skeletal Radiol. 2012:41(2):129-36.
46. Gupta RT, Wadhwa RP, Learch TJ, Herwick SM. Lisfranc injury: imaging findings for this important but often-missed diagnosis. Curr Probl Diagn Radiol. 2008;37(3):115-26

47. Klaue K. Chopart fractures. Injury. 2004;35 Suppl 2:SB64-70.

48. Main BJ, Jowett RL. Injuries of the midtarsal joint. J Bone Joint Surg Br. 1975;57(1):89-97.

49. Ip KY, Lui TH. Isolated dorsal midtarsal (Chopart) dislocation: a case report. J Orthop Surg (Hong Kong). 2006:14(3):357-9.

50. van Dorp KB, de Vries MR, van der Elst M, Schepers T. Chopart joint injury: a study of outcome and morbidity. J Foot Ankle Surg. 2010;49(6):541-5.

51. Benirschke SK, Meinberg E, Anderson SA, Jones CB, Cole PA. Fractures and dislocations of the midfoot: Lisfranc and Chopart injuries. J Bone Joint Surg Am. 2012:94(14):1325-37.

52. Swords MP, Schramski M, Switzer K, Nemec S. Chopart fractures and dislocations. Foot Ankle Clin. 2008:13(4):679-93. viii.

53. Strayer SM, Reece SG, Petrizzi MJ. Fractures of the proximal fifth metatarsal. Am Fam Physician. 1999;59(9):2516-22.

54. Torg JS, Balduini FC, Zelko RR, et al. Fractures of the base of the fifth metatarsal distal to the tuberosity. Classification and guidelines for non-surgical and surgical management. J Bone Joint Surg Am. 1984;66(2):209-14

55. Pao DG, Keats TE, Dussault RG. Avulsion fracture of the base of the fifth metatarsal not seen on conventional radiography of the foot: the need for an additional projection. AJR Am J Roentgenol. 2000;175(2):549-52.

56. Chuckpaiwong B, Queen RM, Easley ME, Nunley JA. Distinguishing Jones and proximal diaphyseal fractures of the fifth metatarsal. Clin Orthop Relat Res. 2008;466(8):1966-70.

57. Zwitser EW, Breederveld RS. Fractures of the fifth metatarsal; diagnosis and treatment. Injury. 2010;41(6):555-62.

\section{Submit your manuscript to a SpringerOpen ${ }^{\odot}$ journal and benefit from:}

- Convenient online submission

- Rigorous peer review

- Immediate publication on acceptance

- Open access: articles freely available online

- High visibility within the field

- Retaining the copyright to your article

Submit your next manuscript at $>$ springeropen.com 